\title{
Impact of in-house specialty pharmacy on access to novel androgen axis inhibitors in men with advanced prostate cancer
}

\author{
Anna Driscoll \\ Thomas Jefferson University, anna.driscoll2@jefferson.edu \\ Nathan Handley, MD, MBA \\ Thomas Jefferson University, nathan.handley@jefferson.edu \\ Adam Binder \\ Thomas Jefferson University, adam.binder@jefferson.edu \\ Siobhan Henry \\ W. Kevin Kelly, DO

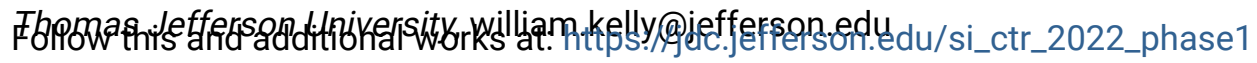 \\ Part of the Oncology Commons, Pharmacy and Pharmaceutical Sciences Commons, and the \\ Translational Medical Research Commons \\ Let us know how access to this document benefits you
}

\section{Recommended Citation}

Driscoll, Anna; Handley, MD, MBA, Nathan; Binder, Adam; Henry, Siobhan; and Kelly, DO, W. Kevin, "Impact of in-house specialty pharmacy on access to novel androgen axis inhibitors in men with advanced prostate cancer" (2020). Phase 1. Paper 77.

https://jdc.jefferson.edu/si_ctr_2022_phase1/77

This Article is brought to you for free and open access by the Jefferson Digital Commons. The Jefferson Digital Commons is a service of Thomas Jefferson University's Center for Teaching and Learning (CTL). The Commons is a showcase for Jefferson books and journals, peer-reviewed scholarly publications, unique historical collections from the University archives, and teaching tools. The Jefferson Digital Commons allows researchers and interested readers anywhere in the world to learn about and keep up to date with Jefferson scholarship. This article has been accepted for inclusion in Phase 1 by an authorized administrator of the Jefferson Digital Commons. For more information, please contact: JeffersonDigitalCommons@jefferson.edu. 


\section{Impact of in-house specialty pharmacy on access to novel androgen axis inhibitors in men with advanced prostate cancer. \\ Anna Driscoll, Nathan Handley MD MBA*, Adam Binder MD, Siobhan Henry, W. Kevin Kelly DO}

Introduction: Novel androgen axis inhibitors are standard of care treatments in advanced prostate cancer. The billed amounts for these medications are often very high, which may create significant financial toxicity for patients and lead to delays in treatment. Our institution implemented an in-house specialty pharmacy in 2014, that provides these medications and evaluates copay assistance options for all patients. We evaluated the program's impact on out of pocket cost (OOP) and turnaround time (TAT).

Methods: We reviewed available internal specialty pharmacy records to identify prescriptions for abiraterone or enzalutamide filled between $1 / 1 / 17$ and $12 / 31 / 18$. Payments were stratified by primary payment (amount reimbursed by the patient's prescription plan based on the benefit's design) and copayment assistance. Turnaround times (TAT) in business days were stratified by prescriptions requiring intervention (prior authorization, copayment assistance, or insufficient inventory) and clean prescriptions (those requiring no intervention).

Results: One thousand four hundred seventeen prescriptions for 175 unique patients requiring abiraterone $(n=869,61.3 \%)$ or enzalutamide $(n=548,38.7 \%)$ were filled through the institution's specialty pharmacy. The average amount paid by primary payer was $\$ 9,492.96$ for a 30 day supply (range: $\$ 3,382.48-\$ 12,939.84)$. Average quoted copay was $\$ 577.53$ (range $\$ 3.08-\$ 10,560.39)$. $64 \%$ of patients received copayment assistance. Average OOP cost per prescription after co-pay assistance was $\$ 100.83$ (range $\$ 0-\$ 8556.64)$. Three patients declined treatment due to cost (1.7\% of overall). Average TAT was 2.98 days for clean prescriptions and 3.36 days for prescriptions needing intervention $(p=0.055)$.

Discussion: OOP cost varied significantly based on plan design and copayment assistance eligibility. The majority of patients received copayment assistance, which markedly reduced OOP cost. Cost rarely precluded access to treatment. TAT was not significantly prolonged for prescriptions requiring intervention. Further studies to determine impact of pharmacy type on access to specialty medications are indicated. 